\title{
DOCUMENTOS DE LOS ULLOA: EL ARCHIVO DE LOS CONDES DE VILLALONSO*
}

\author{
ANTONIO SÁNCHEZ GONZÁLEZ \\ Universidad de Huelva \\ ORCID iD: http://orcid.org/0000-0001-5025-455X
}

* El presente artículo se enmarca en el proyecto de investigación "La casa señorial en Galicia (siglos XIII-XVI). Materiales para su estudio", HAR2017-82480-P, financiado por el Ministerio de Ciencia, Innovación y Universidades (Programa Estatal de Fomento de la Investigación Científica y Técnica de Excelencia. Subprograma Estatal de Generación de Conocimiento), la Agencia Estatal de Investigación (AEI) y el Fondo Europeo de Desarrollo Regional (FEDER), del que es investigador principal el Dr. Pablo S. Otero Piñeyro Maseda.

Copyright: (C) 2021 CSIC. La edición electrónica de esta revista se distribuye bajo los términos de una licencia de uso y distribución Creative Commons Reconocimiento 4.0 Internacional (CC BY 4.0).

Cómo citar/Citation: Antonio SÁnchez GonZÁlez, "Documentos de los Ulloa: el archivo de los Condes de Villalonso", Cuadernos de Estudios Gallegos, 68, núm. 134 (2021), págs. 187211, https://doi.org/10.3989/ceg.2021.134.06 


\title{
DOCUMENTOS DE LOS ULLOA: EL ARCHIVO DE LOS CONDES DE VILLALONSO
}

\author{
RESUMEN \\ El objetivo de este artículo es presentar un fondo documental del Archivo Ducal de Medinace- \\ li, la sección "Villalonso", con varios centenares de documentos del señorío y condado leonés \\ del mismo nombre, en tierras próximas a la ciudad de Toro, que ostentó una rama del linaje \\ Ulloa, procedente de Galicia. \\ El dominio fue erigido en condado en 1599 por el rey Felipe III. Más tarde, a partir del siglo \\ XVII, los condes de Villalonso entroncaron con otras casas nobiliarias peninsulares, pasando \\ su Archivo a incorporarse sucesivamente, primero en el siglo XVIII, al de los duques de San- \\ tisteban del Puerto y, definitivamente en 1818, al de los duques de Medinaceli. \\ En este estudio, tras tratar primero la evolución histórica familiar de estos Ulloa, difundimos \\ los contenidos del archivo condal de Villalonso, perfilamos su sistema de organización docu- \\ mental y trazamos la evolución secular del fondo documental. \\ Palabras Clave: linaje Ulloa, condado de Villalonso, ciudad de Toro, Archivos de familia, \\ documentación patrimonial.
}

\section{DOCUMENTOS DOS ULLOA: O ARQUIVO DOS CONDES DE VILLALONSO}

\section{RESUMO}

O obxectivo deste artigo é presentar un fondo documental do Arquivo Ducal de Medinaceli, a sección "Villalonso", con varios centenares de documentos do señorío e condado leonés do mesmo nome, en terras próximas á cidade de Toro, que ostentou unha rama da liñaxe Ulloa, procedente de Galicia.

O dominio foi erixido en condado en 1599 polo rei Felipe III. Máis tarde, a partir do século XVII, os condes de Villalonso entroncaron con outras casas nobiliarias peninsulares, pasando o seu Arquivo para incorporarse sucesivamente, primeiro no século XVIII, ao dos duques de Santisteban del Puerto e, definitivamente en 1818, ao dos duques de Medinaceli.

Neste estudo, tras tratar primeiro a evolución histórica familiar destes Ulloa, difundimos os contidos do arquivo condal de Villalonso, perfilamos o seu sistema de organización documental e trazamos a evolución secular do fondo documental.

Palabras Clave: liñaxe Ulloa, condado de Villalonso, cidade de Toro, Arquivos de familia, documentación patrimonial.

\section{DOCUMENTS OF THE ULLOA FAMILY: THE ARCHIVE OF THE VILLALONSO COUNTS}

\begin{abstract}
In this paper, we aim to analyse a part of the Ducal Archives of Medinaceli known as the Villalonso section. The archive collection is in fact a large one, containing several hundred documents related to the lordship and county of Villalonso, located near the city of Toro and held by a Galician branch of the Ulloa family.

This estate was declared a county in 1599 by King Felipe II. Afterwards, from the $17^{\text {th }}$ century onwards, the Villalonso Counts became related to other noble Spanish families, and their Archive was successively incorporated, first, to that of the Dukes of Santisteban del Puerto in the $18^{\text {th }}$ century, and later to the Archives of the Dukes of Medinaceli.

In this study, we will deal with the historic evolution of this family branch. Thereafter, we will analyse the contents of these archives, describe their organization, and lay out their evolution through the centuries.

KEY WORDS: Ulloa family, Villalonso County, City of Toro, family archives, patrimonial archives.
\end{abstract}


Recibido/Received: 31/05/2020

Aceptado/Accepted: 19/09/2020

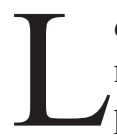

os Ulloa, familia noble procedente de la comarca lucense del mismo nombre, en una de sus ramas pasó en el siglo XIV a tierras zamoranas próximas a Toro, donde fueron regidores de la ciudad. Uno de ellos, Per Yáñez (o Periáñez) de Ulloa, en 1412 adquirió por compraventa los señoríos de Villalonso y Benafarces, que se incluyeron en el mayorazgo familiar fundado en 1529, siendo más adelante el territorio elevado a condado, concretamente en 1599 por el rey Felipe III, con el nombre de Villalonso.

Estos condes heredaron después, por mejor derecho, al marquesado de Malagón con la mariscalía mayor de Castilla y otros dominios, un patrimonio transferido primero a los condes de Castellar y después a la Casa de Santisteban del Puerto. Y agregado a esta se incorporaría en los inicios del siglo XIX a la Casa Ducal de Medinaceli en adelante.

Como consecuencia de ello, el Archivo condal de Villalonso se transfirió a Madrid en el siglo XVIII para incorporarse, primero, al de Santisteban del Puerto en el palacio que estos tenían en la Plaza de San Pedro y, con este en 1818, al Archivo General de la Casa Ducal de Medinaceli en el majestuoso palacio que esta importante casa nobiliaria poseía en la confluencia del Paseo del Prado con la carrera de San Jerónimo. En tales depósitos se acabó de organizar el fondo señorial de los condes de Villalonso, bajo los parámetros establecidos por estos nobles en sus respectivos Archivos.

Nuestro objetivo aquí no es otro que difundir los contenidos del fondo documental de estos Ulloa afincados en tierras zamoranas, perfilar su sistema de organización archivístico durante los siglos XVIII y XIX, así como trazar la evolución secular de toda la documentación en ese tiempo, tras tratar primero la historia familiar de la Casa de Villalonso y su evolución hasta agregarse a los Medinaceli.

Para ello, metodológicamente, no solo hemos trabajado en el fondo documental objeto de estudio, revisando sus inventarios y analizando las marcas dorsales de cada pieza documental, sino también en la documentación de referencia que se conserva en la Real Academia de la Historia, preferentemente la colección Salazar y Castro, así como en otras piezas sueltas del Archivo del Reino de 
Galicia, Archivo Histórico Nacional, Archivo de la Nobleza española y Archivo de la Catedral de Zamora.

CASA, LiNAJE Y TERritorio: El CONDAdo DE Villalonso, un ESTAdo de LOS ULLOA

Una rama de la familia Ulloa procedente de Galicia - concretamente del lugar de Villamayor de Ulloa, cerca de Monterroso, donde tenían casa solar-1 quedó afincada en el siglo XIV en tierras zamoranas de Toro. Algunos genealogistas atribuyen este asentamiento a Juan Pérez de Ulloa, mencionándolo como alcaide de la fortaleza torense y regidor de la ciudad ${ }^{2}$, si bien el afincamiento debió ser con su padre ${ }^{3}$. Casado Juan Pérez de Ulloa con María Yáñez de Andrade, un hijo del matrimonio, Per Yáñez (o Periáñez) de Ulloa, adquirió el 29 de octubre de 1412 las villas cercanas a Toro de Villalonso y Benafarces, por compraventa al señor de Santisteban del Puerto y caudillo mayor del reino de Jaén Día Sánchez de Benavides, con un coste de 2000 florines de oro ${ }^{4}$. De ahí que consideremos a este Per Yáñez como el verdadero tronco y origen de la Casa de Villalonso ${ }^{5}$

No obstante, la fundación de Villa Alonso (Villalonso) se encuadra en el proceso repoblador del alfoz de la propia ciudad de Toro, que promovieron los reyes de León. Así, en tiempos de Alfonso VII el Emperador, le otorgó fuero propio en 1147 para poblarse, juntamente con el lugar de Benafarces, el conde Osorio Martínez $(† 1160)$ y su esposa Teresa Fernández, señora de Villalobos, en nombre

\footnotetext{
${ }^{1}$ Para los orígenes gallegos del linaje Ulloa, además de la obra clásica de Vasco DE APONTE, Recuento de las casas antiguas del reino de Galicia, ed. Manuel C. Díaz y Díaz et al., Santiago de Compostela, Xunta de Galicia, 1986, pág. 162, v. Eduardo Pardo de Guevara Valdés, Pablo Santiago Otero Piñeyro MaSEDA y Xosé Antón GARCÍA GONZÁLEZ-LEDO, "La huella de los primeros Ulloa en las torres y fortalezas de la terra de Ulloa”, Castillos de España: publicación de la Asociación Española de Amigos de los Castillos [ejemplar monográfico de las fortificaciones galaicas], 164-166, (2012), págs. 59-67.

2 Alonso López de Haro, Segunda parte del Nobiliario genealógico de los Reyes y Títulos de España, Madrid, Por la viuda de Fernando Correa de Montenegro, 1622, pág. 446.

${ }^{3}$ Era hijo de Juan Alonso Pérez de Ulloa, señor de la casa de la Puxeda, Pazo de Piñeiro y castillo de La Mota de Toro (v. Archivo Reino de Galicia (en adelante ARG), Fondo Pardo-Ozores, mazo 43, caja 10 núm. 3), nieto del señor de Piñeiro Diego Sánchez de Ulloa y bisnieto del V señor de Villamayor de Ulloa Sancho López de Ulloa. Sobre estas ramas del linaje Ulloa, v. Eduardo PARdo DE GuevarA VALDÉs, Palos, fajas y jaqueles: la fusión de armerías en Galicia durante los siglos XIII al XVI, Lugo, Diputación Provincial, 1996, págs. 143-175. También se refiere al asentamiento de los Ulloa en tierras zamoranas María Josefa SANZ FUENTES, "El señorío de Villalonso: aproximación diplomático-histórica", en El pasado histórico de Castilla y León: [Actas del I Congreso de Historia de Castilla y León celebrado en Valladolid, del 1 al 4 de diciembre de 1982]. Vol. 1: Edad Media, Burgos, Junta de Castilla y León, 1983, pág. 223, nota 5 .

${ }^{4}$ Archivo Ducal de Medinaceli (en adelante ADM), Villalonso, 7-53. Cfr. Antonio SÁnchez GonzÁLEZ, El Archivo de los Caudillos del reino de Jaén (Casa de Santisteban del Puerto), Jaén, Diputación de Jaén, Instituto de Estudios Giennenses, 2015, págs. 34-35 y 73.

5 V. nuestra tabla genealógica VILLALONSO $=$ Ulloa=, que ilustra estas páginas (tabla 1).
} 
propio y de sus hijos ${ }^{6}$. Años después, ya en el reinado de Fernando II de León, un tercio de los diezmos de las iglesias de Villalonso, Benafarces Carvajosa, Grallaneros y Pozoantiguo son donadas por dichos condes a la diócesis de Zamora el 16 de abril de 1159 para la salvación de nuestras almas ${ }^{7} \mathrm{y}$, al año justo, añaden otra tercera parte del diezmo de las mismas iglesias ${ }^{8}$, además de algunas heredades del término que poco antes le habían concedido al propio obispo zamorano 9 . Por otra parte, desde las Cortes de León de 1188 y en adelante, Villalonso sería una de las poblaciones representadas por Toro en las sucesivas Cortes, entre las ciudades con voto ${ }^{10}$.

A partir del siglo XIV, como dijimos, el territorio era señorío laico incluido en el patrimonio que la familia Benavides se granjeó en el reino leonés ${ }^{11}$, de donde procedían $^{12}$, antes de afincarse en el reino de Jaén -del que fueron caudillos de su obispado y señores de Santisteban del Puerto-, hasta que Día Sánchez de Benavides la vende a Per Yáñez de Ulloa, en 1412, por esos 2000 florines de oro.

\footnotetext{
${ }^{6}$ Archivo Histórico Nacional (en adelante AHN), Clero, leg. 2346, doc. transcrito por José Rius SERRA, "Nuevos fueros de tierras de Zamora", Anuario de Historia del Derecho Español, 6 (1929), págs. 444-445; y por Emiliano GonZÁLEz DíEz, El régimen foral vallisoletano. Una perspectiva de análisis del territorio, Valladolid, Instituto de Cultura Simancas, 1985, págs. 100-101.

7 Archivo de la Catedral de Zamora (en adelante ACZ), leg. 8, núm. 11 (Tumbo negro), fol. 1. Cfr. José Luis Martín, Documentos del Archivo Catedralicio de Zamora. Primera parte (1128-1261), Salamanca, Universidad de Salamanca, 1982, pág. 17, doc. 12.

${ }^{8}$ ACZ, leg. 14, núms. 27-28: Tumbo negro, fols. 4-5 y 30. Cfr. MarTín, Documentos del Archivo Catedralicio..., doc. 14.

9 V. Real Academia de la Historia (en adelante RAH), Colección Salazar y Castro (en adelante Col. $S y C$ ), núm. 64624 (doc. 19, aunque, por error, figura en el inventario fechado un siglo antes).

${ }^{10}$ Carlos Javier Salgado Fuentes, La evolución de la identidad regional en los territorios del antiguo Reino de León (Salamanca, Zamora, León), Salamanca, Universidad de Salamanca, 2016, pág. 152. Cfr. Carlos Estepa Díez, "Los inicios de las Cortes en el reinado de Alfonso IX (1188-1230)", en Eduardo Fuentes Ganzo y José Luis Martín Rodríguez (coords.), De las cortes históricas a los parlamentos democráticos: Castilla y León, siglos XII-XXI, Madrid, Dykinson, 2003, págs. 65-75.

${ }^{11}$ Quintanilla Raso, que ha estudiado el patrimonio de estos Benavides en el reino de León, no refiere la fórmula de adquisición del señorío de Villalonso por parte de este linaje (v. María Concepción QuINTANilla RAso, “Aportación al estudio de la Nobleza en la Edad Media: La Casa señorial de Benavides”, Historia. Instituciones. Documentos, 1 (1974), págs. 178-179). Nosotros consideramos que bien podría proceder de una posible transferencia de los Godínez a los Benavides, con quienes emparentaron, o bien del conjunto de bienes confiscados a Martín González en tierras de Toro cuando se sublevó contra el rey durante la minoría de Alfonso XI, y que el monarca donó en 1328 a Juan Alfonso de Benavides "el Mozo", VIII señor de Benavides y portero mayor del reino de León (ADM, Archivo Histórico, caja 45, leg. 287, núm. 10. Cfr. Manuel GARCíA FernÁNDEZ, "Regesto documental andaluz de Alfonso XI (13121350)", Historia. Instituciones. Documentos, 15 (1988), pág. 33 doc. núm. 142). La segunda esposa de este Juan Alfonso, María Girón, adquirió en 1350 unas casas en Toro, compradas por 2000 maravedís a Juan Alfonso de Alburquerque (ADM, Santisteban, 23-22). Lo cierto es que "Villalfonso" figura en el testamento del propio Juan Alfonso Benavides, fechado en 1358, junto con Benafarces y Pozoantiguo (ADM, Santisteban, 21-27). Estos dominios recalarán de nuevo, mucho más tarde, en la propia Casa de Santisteban del Puerto de los Benavides, como condado de Villalonso.

12 V. Sánchez González, El Archivo de los Caudillos del reino de Jaén..., págs. 21-22.
} 
Este mismo Per Yáñez de Ulloa asistió al rey Juan II en la batalla de la vega de Granada y, en recompensa, le premia el monarca castellano con el señorío de Granadilla en Extremadura por albalá de 8 de diciembre de 1429, figurando en el documento como oidor de la audiencia y miembro del consejo real ${ }^{13}$, una merced que es confirmada más tarde por privilegio rodado de 2 de marzo de 1436 del mismo rey ${ }^{14}$. Cuatro años después, concretamente el 3 de agosto en 1440, Juan II le concede también a Per Yáñez la villa de Villena, territorio frontero entre Castilla y Aragón, en enmienda de la de Granadilla ${ }^{15}$, por la ayuda que le prestó como en las negociaciones de paz de Castilla con el reino de Aragón y en premio a su fidelidad a la Corona.

De los dos matrimonios contraídos por Per Yáñez, fue el segundo, con Juana de Herrera, el que le dejó posteridad masculina. El primogénito, Juan de Ulloa I $(† 1476)$, también fue alcaide de la fortaleza de Toro en tiempos de Enrique IV, e incrementó en 1461 la hacienda heredada de su padre mediante la adquisición de algunas posesiones en término de Villalonso por valor de 184000 maravedís ${ }^{16}$. Con su esposa, María Sarmiento, reconstruyó el castillo del lugar, que habían adquirido en 1449 por permuta con Alonso Pérez de Vivero, que fuera contador mayor del rey Juan II, quien lo había comprado previamente a la orden de Alcántara.

Pero por mantenerse partidario de la causa de Juana la Beltraneja, contra los Reyes Católicos, en las guerras civiles de su tiempo por la sucesión del trono de Castilla $^{17}$, Juan de Ulloa no solo perdió la vida en 1476 defendiendo su castillo de Villalonso, sino que la familia perdió también la mayor parte del patrimonio, además de la fortaleza ${ }^{18}$.

\footnotetext{
13 López de Haro, Segunda parte del Nobiliario..., pág. 446. V. ADM, Villalonso, leg. 4, núms. 14-23.

${ }^{14}$ ADM, Privilegios Rodados, núm. 88 (A.- original). Cfr. Antonio SÁnCHEZ GonzÁLEZ, "La colección de Privilegios Rodados originales del Archivo Ducal de Medinaceli (1175-1458)", Lope de Barrientos. Seminario de Cultura, 2 (2009), pág. 263.

${ }^{15}$ Archivo Histórico de la Nobleza (AHNob), Frías, 121-10 y 121-4 a 6. Cfr. Aniceto LóPez SerraNO, "En torno a los problemas y confusión jurídica en la posesión del señorío de Villena (Siglos XV y XVI)”, Miscelánea medieval murciana, 21-22 (1997-1998), pág. 174.

${ }^{16}$ ADM, Villalonso, 1-4.

${ }^{17}$ El rey Alfonso V de Portugal, como esposo de la infanta Juana, encabezó obviamente la defensa de la sucesión de la Beltraneja al trono de Castilla. Ambos, durante la guerra civil castellana, estuvieron algún tiempo refugiados en el castillo de Villalonso, protegidos por Juan de Ulloa y su esposa.

${ }_{18}$ Tras la entrada de las tropas isabelinas en Toro durante aquella contienda, a Juan de Ulloa se le dio por muerto, mientras su viuda permaneció defendiendo aquel castillo durante un mes -con ayuda de su yerno, el conde de Marialva Francisco de Coutiño- hasta que hubo de entregar la fortaleza el 19 de octubre de 1479. A cambio, María Sarmiento conseguía el perdón real para ella y sus hijos, así como la posesión del castillo de Villalonso y de los bienes privados; sin embargo, hubo de entregar algunas otras plazas, como Tiedra y la Mota de Toro (V. Luis SuÁREz Fernández, Los Reyes Católicos: la conquista del trono, Madrid, Rialp, 1989, pág. 175).
} 
Le sucedió el mayor de sus hijos, Diego de Ulloa Sarmiento I, quien con facultad real de 25 de junio de 1513 fundó mayorazgo de sus bienes por escritura otorgada en Toro el 24 de octubre de $1529^{19}$. Dicha licencia venía a suponer un reconocimiento oficial de perdón pues, previamente, este Diego de Ulloa, regidor de Toro, se había aliado con el movimiento comunero y había sido condenado a muerte por el propio emperador Carlos V, librándose de ello por la entrega al fisco real de la importante suma de 10000 ducados $^{20}$.

Heredó después el mayorazgo de Villalonso su primogénito, Juan de Ulloa Sarmiento II, quien con motivo de su matrimonio con Guiomar Pardo Tavera (hermana de Arias Pardo, primer señor de Malagón, y sobrina del célebre cardenal Juan Pardo Tavera, arzobispo de Toledo e inquisidor general ${ }^{21}$ ) daría la posibilidad de una agregación futura a la Casa de este estado manchego.

Fruto de dicho matrimonio nació Diego de Ulloa Pardo-Tavera, IV señor de Villalonso y Benafarces, a quien sucedió en el último cuarto del siglo XVI su hijo Juan Gaspar de Ulloa III, que desarrolló una carrera importante en favor de la monarquía, lo que le acarreó sucesivos nombramientos, primero como mayordomo de la emperatriz María y, luego, también como mayordomo del rey Felipe III $^{22}$. En su persona el monarca elevó el señorío de Villalonso a rango de condado concediéndole este título por privilegio de 26 de febrero de $1599^{23}$.

Para entonces este territorio de los Ulloa estaba más que configurado, desde el siglo XV, en tierras llanas de Zamora, justo en la pequeña zona que giraba por el norte y oeste del término de Toro y se prolongaba por el territorio de la actual provincia de Valladolid. Ahí quedaban emplazados los señoríos de Villalonso y Benafarces y, al suroeste, el lugar anexo de Peleagonzalo. A estos dominios habría que añadir también los lugares de Castroquemado y San Miguel de Grox,

\footnotetext{
${ }^{19}$ ADM, Villalonso, 4-34. V. SANZ FuEnTES, "El señorío de Villalonso...”, pág. 227, nota 36. Una completa relación de tierras y restas y de Diego de Ulloa I a fines del siglo XV en ADM, Villalonso, 5-35. Sus bienes son conocidos por un interesante recuento que se hizo tras su muerte (ADM, Villalonso, 2-31), estudiado específicamente por la misma María Josefa SANZ FuENTES, "Un noble zamorano ante la muerte: testamento, codicilo e inventario post mortem de Diego Ulloa, Señor de Villalonso", en Primer congreso de historia de Zamora. T. I: Fuentes documentales, Zamora, Instituto de Estudios Zamoranos Florián de Ocampo, 1989, págs. 369-388.

${ }^{20}$ Han tratado sobre el movimiento comunero las obras de Juan Ignacio GutiérRez Nieto, Las Comunidades como movimiento antiseñorial: la formación del bando realista en la guerra civil castellana de 1520-1521, Barcelona, Planeta, 1973, págs. 19-122; y Santiago de LuXÁN MELÉNDEZ, "La revolución comunera en las síntesis generales de historia de España (1950-1989)”, Hispania, vol. 50, 176 (1990), págs. 1141-1157. También es muy útil el trabajo colectivo coordinado por Miguel F. GómEz VozMEDiANO, Castilla en llamas. La Mancha comunera, Ciudad Real, Almud, 2008, págs. 15-32.

${ }^{21}$ V. Antonio SÁNChez GonZÁLEZ, "El Hospital de San Juan Bautista en Toledo, una fundación familiar del Cardenal Tavera", Hispania Sacra (en prensa).

${ }^{22}$ López de Haro, Segunda parte del Nobiliario..., pág. 446.

${ }_{23}$ V. Ministerio de Justicia, Guía Oficial de las Grandezas y Títulos del Reino (edic. 2009), pág. 699. No está el documento original en el ADM.
} 


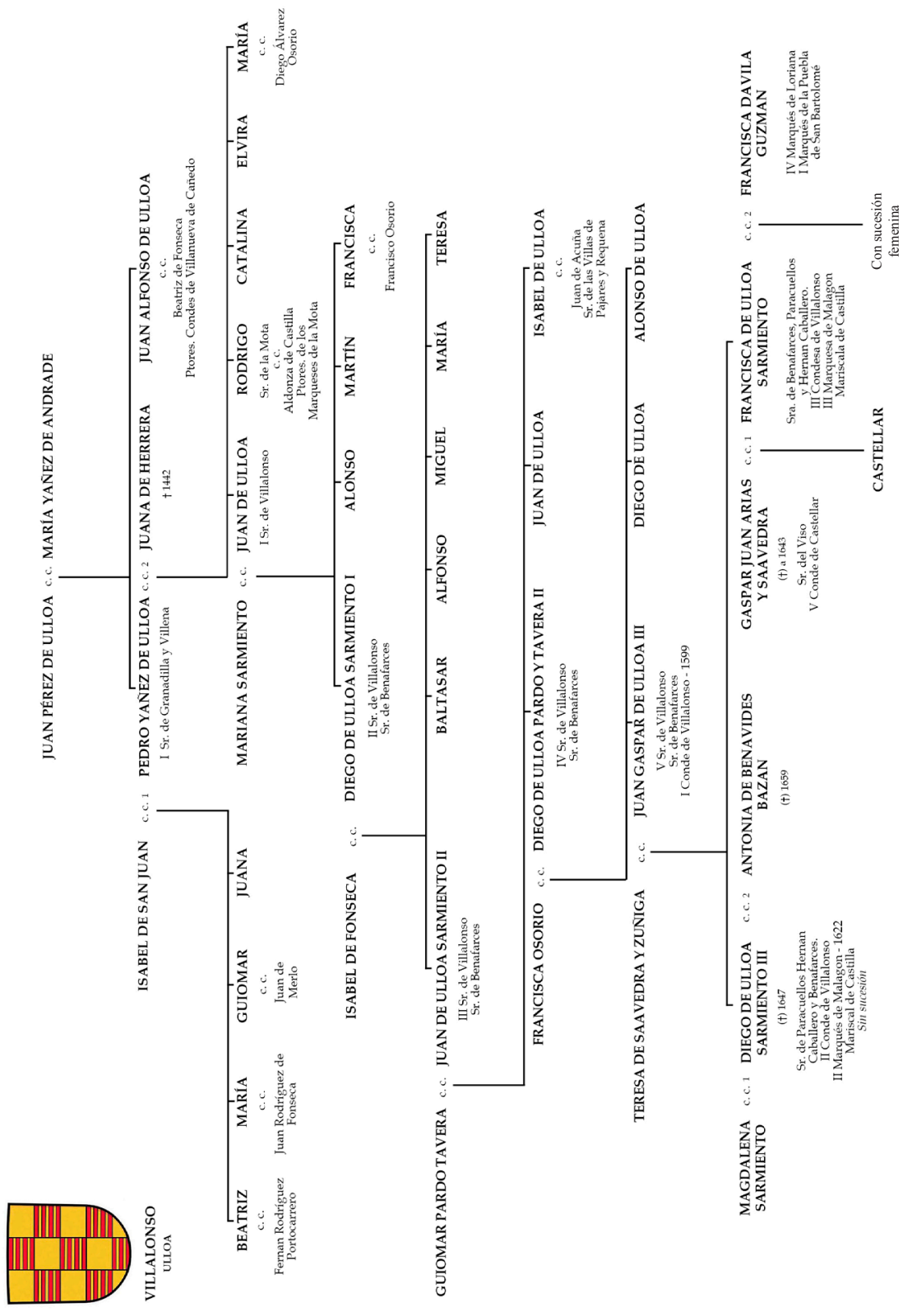

Tabla 1. Genealógica de los señores y condes de Villalonso, rama del linaje Ulloa. 
que quedaron despoblados con el tiempo ${ }^{24}$. La extensión superficial de este pequeño enclave señorial rondaría los cincuenta kilómetros cuadrados.

El primer conde de Villalonso Juan Gaspar de Ulloa III contrajo nupcias con Teresa de Saavedra, única hermana del cuarto conde de Castellar ${ }^{25}$, antesala de una alianza algo posterior de ambas familias que, gracias a este enlace, traería consecuencias transcendentales para el patrimonio de los Ulloa. Del matrimonio nacieron dos hijos y ambos sucederían en la Casa, como comprobamos de inmediato.

El primogénito, un varón llamado Diego de Ulloa Sarmiento III (†1647), heredó el mayorazgo como II conde de Villalonso y señor de Benafarces, estados a los que añadiría, además, por extinción de la línea de primogenitura de los Arias Pardo-Tavera en 1622, el marquesado de Malagón y sus dominios agregados poco después ${ }^{26}$. Este cuarto Diego del linaje, que llegó a ser también mayordomo mayor del rey, se convertía así además en segundo marqués de Malagón y señor de Fernán Caballero y Paracuellos de Jarama, como más propincuo varón y con mejor derecho a la sucesión al descender de una tía de la última titular de esos estados, también llamada Guiomar Pardo, que fue la esposa de su bisabuelo Juan de Ulloa Sarmiento, III señor de Villalonso y Benafarces ${ }^{27}$.

No tuvo ninguna posteridad Diego de Ulloa del matrimonio que contrajo con Antonia de Benavides, una hija de los VII condes de Santisteban del Puerto, ni de otro anterior con su prima Magdalena Sarmiento y Ulloa $(\dagger 1618)^{28}$. Por esa razón, a su muerte en 1647, su hermana Francisca de Ulloa Sarmiento se

\footnotetext{
${ }^{24}$ En el caso de San Miguel de Grox, procede del fondo documental de Villalonso un interesante plano de su término municipal titulado "Planta de la jurisdicción de San Miguel de Grox, en el distrito de Toro, del Señor Marqués de Malagón [y conde de Villalonso]”. V. Antonio SÁnchez GonzÁlez (ed.), El arte de la representación del espacio: mapas y planos de la colección Medinaceli, Huelva, Universidad de Huelva, 2017 (Arias Montano, 125), págs. 394-395, plano núm. 458 comentado con el profesor Mario Ruiz Morales.

${ }^{25}$ De la personalidad de esta condesa, a través del estudio de una serie de cartas suyas, se ha ocupado Elisa GARCía PRIETO, "La gestión femenina del patrimonio nobiliar. Doña Teresa de Saavedra y Zúñiga, condesa de Villalonso: una aristócrata en los reinados de Felipe II y Felipe III", Cuadernos de Historia Moderna, vol. 41, 1 (2016), págs. 109-128. Algunas de estas cartas originales se conservan en la RAH, Col. SyC, A-73, fols. 187-188 (núm. 11351), A-75, fol. 84 (núm. 11680), A-75, fols. 414-415 (núm. 11869), A-77, fols. 300-301 (núm. 12178), A-78, fols. 38-39 (núm. 12261), y A-78, fols. 202-203 (núm. 12348).

${ }^{26}$ Con la muerte ese año, sin descendencia, de Guiomar Pardo Tavera, II Marquesa de Malagón, se extingue la línea de primogenitura de esta Casa y, tras la resolución de una serie de pleitos en cuyo tiempo el marquesado de Malagón estuvo vacante, recayó finalmente el mayorazgo de esta Casa en el referido Diego de Ulloa.

27 V. ADM, Medinaceli-Desvinculación, 287-19.

${ }^{28}$ V. RAH, Col. SyC, A-81, fol. 200 (núm. 13118), N-49, fols. 264-266 (núm. 62693), M-92, fol. 200v. ${ }^{\circ}$ (núm. 56263), M-52, fol. 60 (núm. 52987) y X-39, fols. 100-109 (núm. 73174).
} 
convertía en III condesa de Villalonso, III marquesa de Malagón y señora de Benafarces, Paracuellos y Fernán Caballero, entre otros dominios.

Para entonces la jefe de la Casa de Ulloa había contraído nupcias, desde 1609, con el V conde del Castellar y señor de El Viso Gaspar Juan Arias de Saavedra, su primo hermano, y había enviudado de él ${ }^{29}$. En consecuencia, todos estos estados patrimoniales de los Ulloa y de los extintos Pardo-Tavera pasarían al primogénito de estos, Fernando Miguel Arias de Saavedra y Ulloa (16111651), agregados a la Casa de Castellar, titulándose así VI conde de Castellar, III marqués de Malagón y IV conde de Villalonso, además de mariscal y alfaqueque mayor de Castilla.

Éste había casado en 1632 con Catalina de Acevedo ${ }^{30} \mathrm{y}$, en ausencia de varón del matrimonio - pues Fernando Miguel fue el último en línea de primogenitura-, le sucedía su hija Teresa María Arias de Saavedra, esposa a su vez desde 1664 de Baltasar de la Cueva y Enríquez de Cabrera ${ }^{31}$, un hijo de los duques de Alburquerque que fue fiscal del Real Consejo de las Órdenes, consejero del Real y Supremo Consejo de Indias y gentilhombre de Cámara, además de virrey del Perú entre 1674 y $1678^{32}$.

Sucedió a estos el primogénito del matrimonio, Fernando Joaquín de la Cueva Arias de Saavedra $(\uparrow 1721)$. Pero ante su temprana muerte sin descendencia en 1721, aunque casado con María Antonia Ruiz de Castro Centurión, pasó entonces el mayorazgo a su única hermana, Ana Catalina de la Cueva Arias de Saavedra (1684-1735), titulada desde entonces IX condesa del Castellar y VII de Villalonso, VI marquesa de Malagón y otros títulos. Esta señora era esposa, desde 1707, del X conde de Santisteban del Puerto -y luego I duque de aquel estado- Manuel de Benavides y Aragón, por lo que aquellos títulos y dominios se incorporaron a la Casa de los Caudillos Mayores del reino de Jaén que, como dijimos, eran estos Benavides.

\footnotetext{
${ }^{29}$ V. ADM, Castellar, 5-15. En realidad, Gaspar Juan Arias de Saavedra (1593-1622), casado con Francisca de Ulloa a los catorce años, falleció muy joven, con tan solo veintinueve años, cuando tenía un prometedor futuro. Fue una vida corta pero intensa pues a los quince meses ya era conde, debido a la temprana muerte de su padre, el conde Fernando Arias de Saavedra, héroe en la batalla de Lepanto. Tuvo el matrimonio tres hijos: Fernando Miguel Arias de Saavedra, su sucesor en el señorío de El Viso y condado de Castellar; José Ramírez de Saavedra, que fue marqués de Rivas; y Beatriz Arias de Saavedra, dama de la reina.

${ }^{30}$ ADM, Castellar, 5-16: Capítulos matrimoniales para este enlace (6 de noviembre 1632).

31 ADM, Castellar, 5-25: Capitulaciones matrimoniales.

${ }^{32}$ Francisco FernÁndeZ de Bethencourt, Historia genealógica y heráldica de la Monarquía Española, Casa Real y Grandes de España, t. X, Madrid, Establecimiento Tipográfico de Jaime Rates, 1920, págs. 309-313. Sobre su virreinato, v. Lewis Hanke (ed.), Los virreyes españoles en América durante el gobierno de la Casa de Austria. Perú, t. V, Madrid, Biblioteca de Autores Españoles, 1978, págs. 37-178.
} 
En consecuencia, por esta alianza quedaba agregado el condado de Villalonso de los Ulloa, en adelante, a la Casa de Santisteban del Puerto, arrastrando consigo el condado de Castellar de los Arias de Saavedra y el marquesado de Malagón de los Pardo-Tavera. Y todos juntos, en dicha Casa de Santisteban, se incorporarían a la ducal de Medinaceli a fines del mismo siglo XVIII, al contraer matrimonio en 1764 los entonces herederos de las respectivas casas nobiliarias. Por un lado, Joaquina María de Benavides y Pacheco (1746-1805), marquesa de Solera y luego III duquesa de Santisteban del Puerto - nieta del citado D. Manuel- y, por otro, Luis María Fernández de Córdoba y Gonzaga (1749-1806), marqués de Cogolludo y futuro XIII duque de Medinaceli ${ }^{33}$. El heredero de este vasto patrimonio sería el hijo de ambos, Luis Joaquín Fernández de Córdoba y Benavides (1780-1840), XIV duque de Medinaceli y IV de Santisteban del Puerto, conde de Villalonso y tantos otros títulos, que conoció la abolición de los mayorazgos y del régimen señorial con la introducción del liberalismo en España.

\section{FORMACIÓN DEL ARCHIVO CONDAL Y AGREGACIÓN A UNIDADES ARCHIVÍSTICAS SUPERIORES}

No tenemos certeza del emplazamiento que tuvo el Archivo de los Ulloa, señores y luego condes de Villalonso, en tierras zamoranas. Pero todo hace indicar que radicaría originariamente en el castillo de la propia villa de Villalonso (fig. 1), en plena llanura castellana de la provincia de Zamora, cerca del límite con la provincia de Valladolid, que quedaba conectado con los castillos de Tiedra y Mota (del Marqués).

Fue construido por Juan de Ulloa, I señor del lugar, y su esposa María Sarmiento, sobre una antigua fortificación perteneciente a la orden de Alcántara, que adquirieron, según adelantamos, por permuta en 1449 con su propietario por entonces, Alonso Pérez de Vivero ${ }^{34}$. La estructura del inmueble corresponde al típico castillo-palacio de la escuela vallisoletana de dicho siglo $\mathrm{XV}$, con paredes de piedra de sillería y esquinas rematadas con $\operatorname{cubos}^{35}$. El castillo, como también

\footnotetext{
33 SÁnchez González, El Archivo de los Caudillos del reino de Jaén..., págs. 60-62.

${ }^{34}$ V. Fernando Cobos Guerra y José Javier de Castro Fernández, Castilla y León. Castillos y fortalezas, León, Edilesa, 1998, págs. 164-165. Cfr. Crónica incompleta de los Reyes Católicos 1469-1476, Madrid 1934, págs. 316-317 y María Josefa SANZ FuEnTES, "Villalonso, un castillo en las Comunidades", Castillos de España, 90 (1985), pág. 68.

${ }^{35}$ La torre del homenaje se eleva en el lado norte, con sus almenas y matacanes. Sobre esta fortaleza puede consultarse las obras de SANZ Fuentes, "Villalonso, un castillo en las Comunidades", págs. 6469; y Ángel Luis Palomino LÁzaro, Manuel Moratinos García, Begoña Alonso Ruiz, María Gloria MARTíNEZ GonZÁLEZ, "Villalonso, un castillo señorial en la campiña toresana, a la luz de la investigación arqueológica”, Anuario del Instituto de Estudios Zamoranos Florián de Ocampo, 23 (2006), págs. 51-76. También lo trata la obra general de Jaime Pinilla GonzÁlez, Castillos de Zamora y Salamanca, León, Lancia, 1995, pág. 26.
} 
quedó dicho, jugó un papel muy importante durante la conocida como guerra de Sucesión castellana, entre 1475 a 1479 y, más tarde, en el levantamiento de las Comunidades de Castilla.

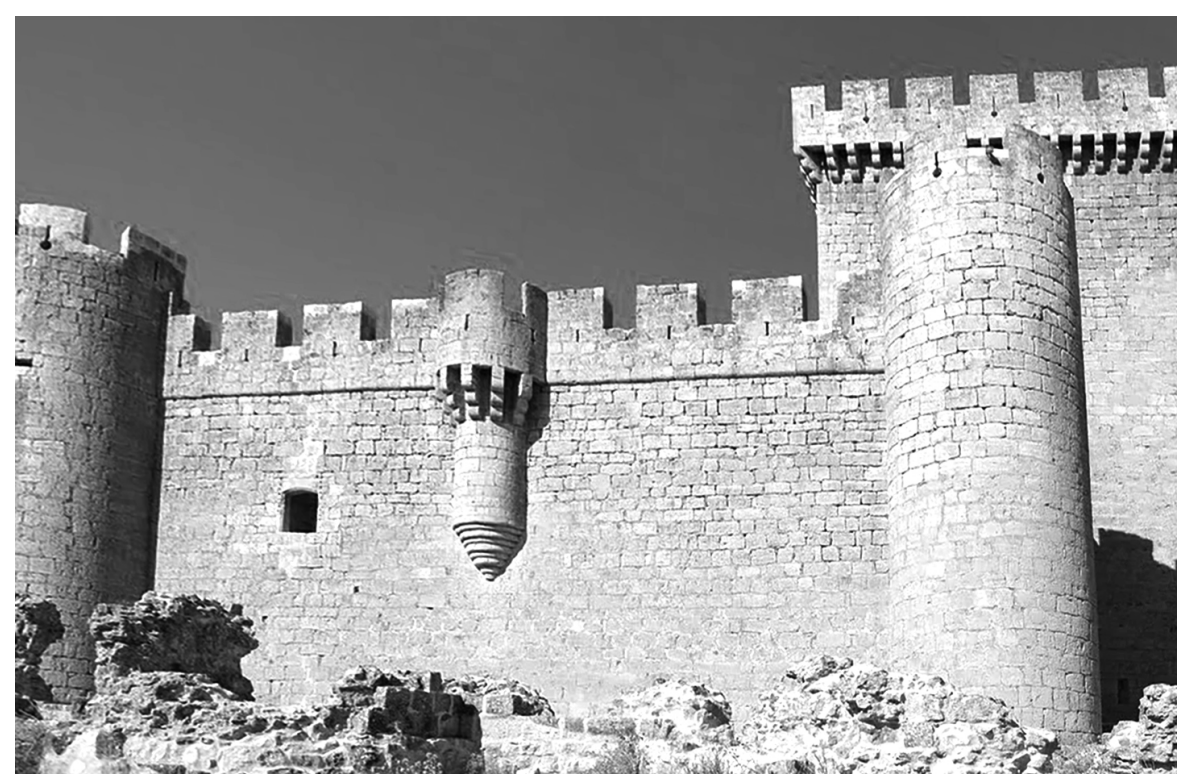

Fig. 1. Castillo de Villalonso.

Igualmente, el Archivo de los Villalonso debió emplazarse durante algún tiempo en las casas-palacio familiares que tenían en la ciudad de Toro, probable sede de la contaduría de los condes.

Más adelante, cuando se incorpora a la Casa de estos Ulloa el marquesado de Malagón, a raíz de los pleitos suscitados en 1622, el Archivo debió permanecer en Villalonso o Toro, pues por entonces no era usual emprender una política de concentración archivística en los depósitos documentales de las casas nobiliarias $^{36}$. Lo mismo ocurre cuando el condado de Villalonso se incorpora, a mediados del mismo siglo XVII, a la Casa de Castellar $^{37}$. E incluso cuando todos esos títulos, estados y propiedades se agregaron en las primeras décadas del siglo XVIII a los de la Casa de Santisteban del Puerto no parece que sus titulares

\footnotetext{
${ }^{36}$ El Archivo del marquesado de Malagón se emplazaba entonces en la propia villa manchega, cabecera de aquel estado, dentro de su castillo-palacio. Allí se depositarían también los fondos del señorío colindante de Fernán Caballero. En cambio, el del señorío de Paracuellos estaría en este lugar, próximo a Madrid.

${ }^{37}$ El Archivo del condado de Castellar de la Frontera radicaba, por entonces, en el castillo-fortaleza de esta villa gaditana cercana a Gibraltar.
} 
tuvieran previsto aún ningún tipo de medidas tendentes a la concentración de los dispersos depósitos documentales, al menos en un primer momento.

Sin embargo, poco después de la incorporación efectiva del condado de Villalonso y de todos esos otros estados que se unen, conjuntamente, a la Casa de Santisteban del Puerto, la política de concentración archivística de los Benavides no se hará esperar.

Estos condes -duques a partir de 1739- tenían por entonces su morada principal en Madrid, en la casa principal o "Casa Grande" que poseía la familia Benavides frente a la iglesia de San Pedro el Viejo, esquina a la calle del Nun$\mathrm{cio}^{38}$. Y, por entonces, los Santisteban aplicaron una política de concentración archivística ordenando las transferencias hasta aquel edificio madrileño de los numerosos fondos documentales que la Casa tenía repartidos por sus numerosos estados señoriales. De ahí que, entre 1720 y 1751, fueran llegando paulatinamente hasta el depósito de aquella casa-palacio los diferentes Archivos de esos diversos estados agregados ${ }^{39}$, principalmente por los años treinta.

El primer conjunto documental que tomó rumbo a la capital fue precisamente el del estado principal de Santisteban del Puerto y los de sus señoríos próximos y agregados de Solera, Espelúy e Ibros, lo que resulta del todo lógico. Estos fondos formarían, por tanto, el embrión o núcleo forjador del Archivo General de la Casa. Los restantes integrantes se irían agrupando paulatinamente al depósito archivístico e incluso algunos de ellos se resistirían a llegar por el momento.

En este sentido, los primeros que se encuentran en Madrid fueron precisamente los fondos de los estados que Ana Catalina de la Cueva Arias de Saavedra, la esposa del conde Manuel de Benavides, por derecho propio había heredado en 1721, entre ellos el condado de Villalonso. Recordemos que, en dicho año, esta señora había sucedido a su hermano Fernando Joaquín, por muerte sin descendencia, y se titulaba IX condesa de Castellar, VI marquesa de Malagón y VII condesa de Villalonso. Y, como decimos, los archivos de estos estados ya se encuentran en la capital del reino, junto al de Santisteban, al iniciarse la tercera década de la centuria ${ }^{40}$.

Más adelante, a raíz del enlace matrimonial contraído en 1764 entre la futura IX condesa de Villalonso y III duquesa de Santisteban del Puerto Joaquina María

\footnotetext{
38 Sobre esta casa-palacio, v. ADM, Santisteban, 28-12 a 30. Cfr. SÁnchEZ GonZÁLEz, El Archivo de los Caudillos del reino de Jaén..., págs. 109-112.

39 Para todo el proceso de concentración archivística de los diversos fondos, v. SÁNCHEZ GonZÁLEZ, El Archivo de los Caudillos del reino de Jaén..., págs. 103-108. El 2 de agosto de 1735 el aún conde de Santisteban Manuel de Benavides emite una orden desde Nápoles para que los administradores de sus estados (bajo cuya custodia aún quedaban sus respectivos fondos) remitiesen las escrituras a Madrid (ADM, Santisteban, 39-2-2).

40 V. ADM, Santisteban, 39-2 (2).
} 
de Benavides y Pacheco - heredera de la Casa en 1782- con el futuro XIII duque de Medinaceli y otros títulos Luis María Fernández de Córdoba y Gonzaga -heredero de la suya en 1789-, se fraguaría la unión de ambas importantes casas nobiliarias españolas y, consecuencia de ello, se propiciaría la ulterior integración de ambos Archivos generales en un depósito único.

Así, pasado el convulso período de la Guerra de la Independencia española (1808-1814), durante el que estos duques fueron declarados proscritos y sus bienes confiscados por Napoleón, el heredero Luis Joaquín Fernández de Córdoba y Benavides ordenaría la transferencia del Archivo de Santisteban en la Plaza de San Pedro al Archivo Ducal de Medinaceli, ubicado en el majestuoso palacio que estos tenían en el Paseo del Prado, una concentración de fondos - como el del condado de Villalonso- que se produjo en 1818.

$\mathrm{Y}$, en adelante, la documentación que aquí tratamos ya no abandonaría el Archivo Ducal de Medinaceli, radicando tanto en dicho palacio madrileño (18181961) como después en la "Casa de Pilatos" de Sevilla (1961-1995) y, por último, en Toledo - desde 1995-, con sede en el Palacio Tavera (antiguo Hospital de San Juan Bautista), donde hoy permanece.

\section{ORGANIZACIÓN Y DESCRIPCIÓN DOCUMENTAL}

El principal artífice inicial de las tareas orgánicas y descriptivas sobre los fondos archivísticos de la Casa de Santisteban del Puerto, al que quedó inicialmente integrado el condal de Villalonso, fue el archivero Manuel Antonio Brochero (1735-1773) $)^{41}$. Conocemos su labor gracias a un informe que elaboró a requerimiento del marqués de Solera, heredero de la Casa, para remitirlo a Italia al conde, su padre, donde por entonces servía al rey de Nápoles (futuro Carlos III de España), para mantenerle informado ${ }^{42}$. Dicho informe, autógrafo y firmado por Brochero, aunque carece de fecha, debió haberlo realizado entre $1735 \mathrm{y}$ $1737^{43}$ y de su tenor se desprende el estado de disposición documental de los fondos del depósito madrileño de los Santisteban por aquellas fechas señalando, al respecto, que

\footnotetext{
${ }^{4}$ V. SÁnchez GonzÁLez, El Archivo de los Caudillos del reino de Jaén..., págs. 113-139. Más adelante, en esta misma fase inicial, prosiguió estas labores en el depósito archivístico el también archivero Manuel de Terán (1783-1802).

${ }^{42}$ Al ocupar, en 1734, el trono de Nápoles el infante D. Carlos (como Carlos VII de Nápoles), el entonces conde de Santisteban Manuel de Benavides -por recomendación de la reina Isabel de Farnesio, madre del nuevo rey napolitano- acudió a Nápoles como tutor del joven monarca y allí será su principal ministro hasta 1738 , año en que regresa a Madrid.

${ }^{43}$ ADM, Santisteban, 39-2 (expte. 2). Transcrito el informe en Antonio SÁnCHEZ GonzÁLEZ, El Archivo de los Caudillos del reino de Jaén..., págs. 267-268 (apéndice documental núm. 6).
} 
Los dos estados de Villalonso y la Mota están sin cajones y necesitan dos; están sus papeles abstractados, puestos en legajos y copiados de mi puño, y autorizados de Pablo Ortiz todos los que han de servir en el pleito ${ }^{44}$.

Esta mención al fondo Villalonso viene a confirmarnos que el Archivo condal ya había llegado a la Casa Grande madrileña de los Santisteban en esos años. Había, pues, una sección "Villalonso", entre las 17 que componían por entonces el Archivo Ducal de Santisteban (una para cada uno de los estados y dominios señoriales) ${ }^{45}$, colocada en un estante del depósito y no en cajones o "papeleras".

En estricta aplicación del principio de respeto a la procedencia de los fondos, quedó conformado el organigrama del Archivo, procediendo a la clasificación archivística el archivero Brochero describiendo algunas secciones (entre las que se incluye la de Villalonso) pieza a pieza, cada una en su envoltura, donde anotó los extractos (“de mi puño") ${ }^{46}$. Pese a la amplitud desorbitada de algunas regestas, que se convierten en casi una transcripción de la pieza documental ${ }^{47}$, en general, estas relaciones de contenido adolecieron de alguna imprecisión ${ }^{48}$.

A continuación, el archivero formó series con la documentación de cada fondo, unas series por lo general demasiado ambiguas, genéricas y concisas o poco aclaratorias ("títulos de dominio", "títulos de posesión", "pertenencias de...", "legajo indiferente", etc.), junto a otras más precisas (“cuentas", "censos", "alcabalas", "dotes y arras", etc.).

Luego se procedió a la ordenación de los documentos siguiendo un criterio cronológico, que se combinó con otro numérico, pues cada escritura así ordena-

\footnotetext{
44 ADM, Santisteban, 39-2 (expte. 2), fol. 2.

${ }^{45}$ Además de esta sección Villalonso, las restantes secciones del depósito introducidas en cajones o papeleras -una por sección-: tres para el estado del Castellar (El Viso, Castellar y Sevilla), cuatro para el estado de Malagón (Paracuellos, Malagón, Sevilla y Toledo), cinco para el estado principal de Santisteban del Puerto (Solera, Santisteban, Espelúy, Ibros y Jaén), tres para el estado de Las Navas (Villafranca, Las Navas y Ávila) y una última para el estado de Medellín. De inmediato se redujeron las secciones a 15 , al integrarse los papeles del estado de Castellar de la administración de Sevilla en la de El Viso, por un lado, y de la administración de Toledo en la de Malagón, para el caso de este estado manchego, por otro. ${ }^{46}$ ADM, Santisteban, 39-2 (expte. 2). Informe del estado del Archivo en torno a 1735. Añade Brochero en este documento autógrafo suyo: haviendo leydo más de 50.000 ojas [...] para sacar la substancia. Estas regestas descriptoras solían ser bastante amplias, lo que en muchos casos le obligó a utilizar doble papel como envoltura o "guarda" de la unidad documental.

${ }_{47}$ V. ADM, Partido de Ávila, 6-13 (antes Medinaceli, 168-13). Cfr. Inventario del Partido de Ávila, págs. 513 a 640 (regesta del doc. aludido).

${ }^{48}$ Ello obligó en el futuro a renovar estas regestas imprecisas de Brochero, mejorándolas de contenido (v. ADM, Partido de Ávila, 16-51 -antes Medinaceli, 178-51-: nota archivística que encabeza la serie). Y ello, además, dejó secuelas en los inventarios en forma de tachaduras y adiciones (v. Libro del Estado de Medellín, págs. 1-7; o Libro del Partido de Ávila, pág. 1.323).
} 
da recibió un número correlativo dentro de su serie. Y se formaron legajos con los documentos ordenados, que también se numeraron correlativamente.

Fruto de este trabajo orgánico desarrollado por Brochero en el depósito documental de los Benavides en Madrid fue la elaboración de 15 tomos inventarios, donde quedó refrendada toda su tarea archivística. La finalidad de estos inventarios nos la presenta el propio Manuel Antonio Brochero indicándonos que tenían esta triple funcionalidad:

para el régimen del Archivo, para la busca de papeles; para el de la Contaduría, para que la conste la hacienda; y para que respectivamente sepa la Secretaría los patronatos, provisiones y regalías de la Casa $^{49}$.

Concretamente el inventario que aquí nos interesa es el que lleva por título Libro del Estado de Villalonso que, aunque no lleva fecha, fue elaborado a mediados del siglo XVIII. Encuadernado en tafilete marrón con sus fundas de vada$n a$ [sic] y con grecas y decoración vegetal grabada en oro fino, al clásico estilo barroco español, con formato de marca mayor y broche-cierre metálico, el tomo se compone de 689 páginas manuscritas, de las que se utilizaron las 360 páginas descriptoras iniciales pues no hubo necesidad de utilizar la segunda parte del inventario (salvo las páginas 369-373 del tomo, que sirvieron para completar las regestas).

Abre el inventario el escudo de los Ulloa, condes del estado, seguido de la tabla-índice de materias en las que el tomo quedó estructurado.

Todo hace indicar que a mediados del siglo XVIII ya había culminado M. A. Brochero la labor orgánica de los fondos de todos los estados de la Casa de Santisteban del Puerto, incluidos los del condado de Villalonso, excepción hecha de los del condado de Cocentaina que no llegaron a Madrid hasta el año 1751.

La valoración final al trabajo orgánico del primer archivero del conjunto documental de Santisteban podemos calificarla solo de aceptable. En el "debe" de Brochero queda fundamentalmente la creación, en la clasificación, de series muy vagas e imprecisas (que serían, más adelante, parcialmente corregidas por otros archiveros $)^{50}$. Las regestas que compuso fueron tan extensas, en la mayoría

\footnotetext{
${ }^{49}$ ADM, Santisteban, 39-2 (expte. 2). Ello quiere decir que estos instrumentos de descripción del Archivo General de Santisteban constituían una auténtica herramienta de primera mano para la gestión de la propia Casa Ducal en sus tres principales órganos administrativos: Secretaría, Contaduría y Archivo. Hecho que podemos generalizar y aplicar en su totalidad a cualquier Casa de la alta nobleza española.

${ }^{50}$ Esto repercutió en que, aún en nuestros días, resulte complejo a veces localizar un determinado documento dentro del fondo.
} 
de los casos, que hacían perder el hilo del extracto (cantidad informativa que, al menos aquí, no es sinónimo de calidad en la transmisión de datos). Por otro lado, el sistema de orden impuesto en la organización documental no sirvió para mantener el rigor cronológico deseado en la disposición de los fondos, aunque este criterio cronológico era el que se había buscado previamente. En su disculpa cabe indicar la inmensa tarea que realizó, cuantitativamente hablando, por sí solo y con escasísima ayuda ${ }^{51}$.

Una vez concluida la etapa de Brochero como archivero en 1773, el Archivo Ducal de Santisteban quedó reglamentado por las Instrucciones dadas desde Aranjuez, el 8 de junio de ese mismo año ${ }^{52}$ por Antonio de Benavides, VIII conde de Villalonso y II duque de Santisteban, al poco de nombrar nuevo archivero mayor a José Manuel de la Vega (1773-1782) ${ }^{53}$, una fase transitoria en el depósito desde el punto de vista orgánico ${ }^{54}$.

Y con el relevo en la jefatura de la Casa de Santisteban-Villalonso, en 1782, al suceder Joaquina María de Benavides y Pacheco, también debió declinar la gestión de J. M. de la Vega a cargo del Archivo, ascendiendo en el oficio Manuel de Terán (1783-1802), que era oficial del mismo desde 178055. Este sería el artífice de la conclusión y complementariedad de la organización documental de los fondos del Archivo ${ }^{56}$, con innovaciones intranscendentes, si bien su labor apenas afectó al fondo del condado de Villalonso, que se mantuvo por entonces en el estado en que lo había dejado Brochero.

Entrado el siglo XIX, con la agregación de la Casa de Santisteban a la de Medinaceli personalizada en el duque heredero Luis Joaquín Fernández de Córdoba y Benavides, además X conde de Villalonso, se va a producir un intento de homogeneización de los fondos de un Archivo y otro (Santisteban y Medinaceli), ambos en Madrid, sobre todo a raíz de la transferencia del primero, en 1818, al palacio de los Medinaceli en el Paseo del Prado ${ }^{57}$. Por orden ducal de 4 de abril

\footnotetext{
${ }^{51}$ Brochero no contó con un oficial, ni siquiera con algún copista. Él es quien describe todos y cada uno de los documentos, quien escribe de su puño los 15 inventarios que compuso, incluido el de Medellín, y quien transcribe muchos diplomas que lo requerían. Fue escasa, por tanto, la ayuda que recibió de la Casa Ducal y mucho lo que se le exigió, al contrario - por ejemplo- que a su sucesor en el cargo.

${ }^{52}$ ADM, Santisteban, 39-2 (expte. 5: doc. inserto en la ratificación de 26 de marzo de 1799, que tuvo dicha Instrucción).

${ }^{53}$ V. SÁnchez González, El Archivo de los Caudillos del reino de Jaén..., págs. 140-144. Una comparación de este reglamento con otro del Archivo Ducal de Medinaceli, elaborado el mismo año, en Antonio SÁnchez GonZÁlez, "Dos desconocidos reglamentos de archivos", Vegueta: Anuario de la Facultad de Geografia e Historia, 16 (2016), págs. 481-506.

${ }^{54}$ Este archivero, en realidad, aportó muy poco (v. SÁnchez GonzÁlez, El Archivo de los Caudillos del reino de Jaén..., págs. 131-133).

55 ADM, Santisteban, 39-2 (exptes. 5 y 7).

56 V. SÁnchez GonzÁlez, El Archivo de los Caudillos del reino de Jaén..., págs. 133-139.

${ }^{57}$ Más datos en SÁnchez GonzÁlez, El Archivo de los Caudillos del reino de Jaén..., págs. 149-160.
} 
de ese año, el Archivo de Santisteban se incorporaba así al de Medinaceli, bajo la dirección única del archivero Juan Gil de Arana, ocupando una dependencia aparte, aledaña al antiguo depósito, en el propio palacio del Prado ${ }^{58}$.

Ya a fines del mismo siglo XIX, se va a consumar la organización total de los fondos y su descripción general. Así, cuando se realizó un recuento global de la documentación de los depósitos archivísticos de los duques de Medinaceli ${ }^{59}$ por parte del archivero-bibliotecario de José María Octavio de Toledo en $1886^{60}$, el fondo concreto del condado de Villalonso se componía de 16 legajos, y se hallaba custodiado en cuatro papeleras (las dos últimas vacías), tal como aquí recogemos.

\begin{tabular}{|c|l|c|c|c|}
\hline SignATURA & \multicolumn{1}{|c|}{ SERIES } & $\begin{array}{c}\text { NúM. } \\
\text { LEGAJOS }\end{array}$ & $\begin{array}{c}\text { NúM. } \\
\text { Docs. } \\
\text { SUELTOS }\end{array}$ & $\begin{array}{c}\text { NúM. } \\
\text { LiBROS }\end{array}$ \\
\hline Papelera 1. $^{\mathrm{a}}$ & Papeles sueltos & 1 & & \\
\hline Papelera 2. & $\begin{array}{l}\text { Papeles referentes a este estado de Villa- } \\
\text { lonso (legs. 1 a 15) }\end{array}$ & 15 & & \\
\hline Papelera 3. & ---vacía--- & & & \\
\hline Papelera 4. & ---vacía--- & & & \\
\hline
\end{tabular}

Tabla 2. Disposición del fondo del condado de Villalonso en el Archivo Ducal de Medinaceli proveniente de la Casa de Santisteban del Puerto (1886).

Para entonces ya estaba vigente en el Archivo ducal el nuevo ciclo archivístico que nosotros denominamos de la "Desvinculación señorial" mantiene, bastante generalizado entre la nobleza española coetánea. Este nuevo ciclo trajo consigo una serie de intervenciones archivísticas sobre los fondos consistente, por un lado en un cambio en cuanto al sistema de instalación documental, por otro en un reajuste de las secciones del depósito y, por último, en una modificación los instrumentos de descripción, estableciendo incluso los cauces para la futura archivación ${ }^{62}$.

\footnotetext{
${ }^{58}$ Arana fue un leal servidor de la Casa pues defendió los Archivos y todo el patrimonio ducal como si fuera suyo durante los difíciles años de la guerra de la Independencia (v. SÁnchez GonZÁLez, El Archivo de los Caudillos del reino de Jaén..., págs. 152-167).

${ }^{59}$ Antonio SÁnchez González, El Archivo de los Adelantados de Andalucia (Casa de Alcalá), Sevilla, Universidad de Sevilla, 2014, pág. 97.

${ }^{60}$ El Archivo Ducal de Medinaceli, en su conjunto, estaba entonces integrado en 42 secciones, con 3864 legajos, 502 libros y 37 documentos sueltos, que se custodiaban en las 460 papeleras del depósito.

${ }^{61}$ Se trata del período que arranca con la abolición de los mayorazgos y de los señoríos jurisdiccionales, que coincide con la entrada del régimen político del liberalismo en España, en el que la nobleza sufre una gran transformación que afectó también a sus Archivos.

${ }_{62}$ SÁnchez GonzÁlez, El Archivo de los Adelantados de Andalucía..., págs. 104-109.
} 
En cuanto al modo de instalación documental, el cambio consistió en la sustitución de las antiguas papeleras de los depósitos del Archivo General de los Medinaceli por legajos - los mismos que hoy se conservan-que se colocaron en estanterías abiertas, con lo que se modificaba la tradicional reconditez y el carácter arcano que habían caracterizado a los fondos archivísticos durante el Antiguo Régimen por un sistema más abierto y perceptible. Dicho cambio se produjo a fines del siglo XIX y se materializó por el archivero Antonio Paz y Mélia, que fuera jefe del Departamento de Manuscritos de la Biblioteca Nacional y miembro del cuerpo de Archiveros, Bibliotecarios y Anticuarios españoles.

Entonces se mantuvo la sección "Villalonso", con siete legajos como hoy, cuya estructura queda de manifiesto en el cuadro de clasificación del antiguo fondo que aquí recogemos:

\section{Gestión DE LA DOCUMENTACiÓN}

1.1. Apuntamientos: informes de los archiveros y decretos del Archivo

1.2. Árboles genealógicos de los señores y condes de Villalonso

2. DeSCENDENCIA Y SUCESIÓN

2.1. Capitulaciones matrimoniales, dotes, dispensas y curadurías

2.2. Facultades, fundaciones y agregaciones de mayorazgos

2.3. Testamentos y codicilos

3. PATRIMONIO

3.1. Títulos de dominio y jurisdicción del condado

3.2. Villas de Villalonso y Benafarces

3.3. Lugares de San Miguel de Grox, Castroquemado y Peleagonzalo, en término de Toro

3.4. Villas de Villena (Alicante) y Granadilla (Cáceres)

3.5. Heredades de Cillero de Toro, Mompodre y San Juan de Lobones

3.6. Otros bienes sueltos

4. Patronatos y CAPELlanías

4.1. Convento de la Concepción de mercedarias de Toro

4.2. Curatos

5. DOCUMENTACIÓN DE RECUENTO Y CONTROL

5.1. Particiones de bienes e inventarios de hacienda

5.2. Inventarios de escrituras 
6. OFICIOS Y DIGNIDADES

6.1. Oficios de regidores y escribanos de millones de Toro

7 CONTABILIDAD

7.1 Rentas del condado: libro de riquezas

7.2. Censos y alcabalas

7.3. Portazgos y martiniegas de Toro y Zamora

8. Pleitos

8.1. Por la posesión del estado

9. VARIOS

9.1. "Legajo indiferente": cédulas y mercedes reales, pleitos-homenajes, etc.

Así estructurada es como se ha transmitido la documentación del condado de Villalonso hasta nuestros días.

\section{CONCLuSiones}

Este antiguo fondo documental se compone de varios centenares de diplomas, custodiados hoy en su mayor parte en esos siete legajos del Archivo de la Fundación Casa Ducal de Medinaceli ${ }^{63}$, más algunas piezas sueltas o pequeñas series distribuidas en las secciones -también de estados señoriales con los que la Casa de Villalonso tuvo relación parental- de "Santisteban", "Castellar" y "Malagón".

También hay documentación suelta del fondo Villalonso en la miscelánea denominada "Archivo Histórico" y en la facticia de "Privilegios rodados", todas del mismo depósito. A fines del siglo XIX y en los comienzos del XX, con el archivero Paz y Mélia, pasaron a formar parte de dicha miscelánea histórica la serie documental del fondo referida a la correspondencia real y particular de algunos condes de aquel estado zamorano, así como un grupo de reales cédulas y provisiones de concesión de títulos y otros privilegios, además de abundante

\footnotetext{
${ }^{63}$ V. SANZ Fuentes, "El señorío de Villalonso: aproximación diplomático-histórica”, págs. 222-223. Un trabajo específico de la documentación de este fondo es el titulado, de la misma María Josefa SANZ FUENTES, "Contribución a la sigilografía eclesiástica española: sellos de obispos zamoranos en la sección Villalonso del Archivo Ducal de Medinaceli”, Gades, 9 (1982), págs. 311-330.
} 
correspondencia de valija diplomática de algunos condes y duques ${ }^{64}$, aparte otra correspondencia y documentación sobre funciones gubernativas desempeñadas por algunos de estos nobles en Italia, Perú, etc. ${ }^{65}$. Parte de esta documentación ya ha sido dada a conocer, pero solo en aspectos muy parciales ${ }^{66}$, estando pendiente una obra de conjunto sobre este condado de la ribera del Duero.

De este antiguo fondo, el Archivo de la Casa Ducal de Medinaceli conserva como instrumento de descripción útil aquel antiguo inventario denominado $\mathrm{Li}$ bro de Estado de Villalonso de mediados del siglo XVIII, refrendo de cuando se organizó la mayor parte de la documentación del estado, junto con las fichas catalográficas realizadas por Paz y Mélia a fines del siglo XIX que aún se conservan. El propio sistema orgánico que se estableció en este fondo -como en el resto del Archivo- con la documentación, pieza a pieza, descrita en las carpetillas o "guardas" de cada documento realizada por los distintos archiveros que llevaron a cabo el trabajo orgánico y corregida y completada después por el propio Paz y Mélia, ayuda a la identificación y conocimiento del contenido de toda la documentación del fondo.

Sirva, además, de contribución al conocimiento de este antiguo fondo la guía que incluimos nosotros aquí en Anexo, con descripción de sus series, las fechas extremas y la signatura de localización de los documentos, como aportación para quien necesite la consulta de esta documentación zamorana que forma parte del Archivo General de la Fundación Casa Ducal de Medinaceli.

\section{BIBLIOGRAFÍA}

Aponte, Vasco de, Recuento de las casas antiguas del reino de Galicia, ed. Manuel C. Díaz y Díaz, et al., Santiago de Compostela, Xunta de Galicia, 1986.

Cobos Guerra, Fernando, y Castro Fernández, José Javier de, Castilla y León. Castillos y fortalezas, León, Edilesa, 1998.

Estepa Díez, Carlos, "Los inicios de las Cortes en el reinado de Alfonso IX (1188-1230)", en Eduardo Fuentes Ganzo y José Luis Martín Rodríguez (coords.), De las cortes históricas a los parlamentos democráticos: Castilla y León, siglos XII-XXI, Madrid, Dykinson, 2003, págs. 65-75.

\footnotetext{
${ }^{64}$ De los condes Manuel y Antonio de Benavides, I duque y II duque de Santisteban del Puerto, respectivamente. V. ADM, Archivo Histórico, leg. 80, núms. 49-74.

${ }^{65}$ ADM, Archivo Histórico, leg. 74, ramos 10 a 15, y leg. 75, ramos 1 a 40, más leg. 80, ramo 24, docs. 1 a 28.

${ }^{66}$ Es el caso, entre otros, del conde que fue virrey del Perú [v. Antonio SÁnchez GonZÁlez, "Papeles de ida y vuelta del virrey del Perú Diego de Benavides (1660-1666)", en Reyes Rojas (coord.), El Archivo General de Indias: El valor del documento y la escritura en el gobierno de América, Madrid, Ministerio de Cultura, 2016, págs. 239-250].
} 
Fernández de Bethencourt, Francisco, Historia genealógica y heráldica de la Monarquía Española, Casa Real y Grandes de España, t. X, Madrid, Establecimiento Tipográfico de Jaime Rates, 1920.

García Fernández, Manuel, "Regesto documental andaluz de Alfonso XI (1312-1350)", Historia. Instituciones. Documentos, 15 (1988), págs. 1-125.

García Prieto, Elisa, "La gestión femenina del patrimonio nobiliar. Doña Teresa de Saavedra y Zúñiga, condesa de Villalonso: una aristócrata en los reinados de Felipe II y Felipe III", Cuadernos de Historia Moderna, vol. 41, núm. 1 (2016), págs. 109-128.

González Díez, Emiliano, El régimen foral vallisoletano. Una perspectiva de análisis del territorio, Valladolid, Instituto de Cultura Simancas, 1985.

Hanke, Lewis (ed.), Los virreyes españoles en América durante el gobierno de la Casa de Austria. Perú, t. V, Madrid, Biblioteca de Autores Españoles, 1978.

López de Haro, Alonso, Segunda parte del Nobiliario genealógico de los Reyes y Títulos de España, Madrid, Por la viuda de Fernando Correa de Montenegro, 1622.

López Serrano, Aniceto, "En torno a los problemas y confusión jurídica en la posesión del señorío de Villena (Siglos XV y XVI)", Miscelánea medieval murciana, 21-22 (19971998), págs. 171-214.

Luxán Meléndez, Santiago de, "La revolución comunera en las síntesis generales de historia de España (1950-1989)”, Hispania, vol. 50, núm. 176 (1990), págs. 1141-1157.

Martín, José Luis, Documentos del Archivo Catedralicio de Zamora. Primera parte (11281261), Salamanca, Universidad de Salamanca, 1982.

Ministerio de Cultura, Guía Oficial de las Grandezas y Títulos del Reino, Madrid, 2009.

Palomino Lázaro, Ángel Luis; Moratinos García, Manuel; Alonso Ruiz, Begoña, y Martínez González, María Gloria, "Villalonso, un castillo señorial en la campiña toresana, a la luz de la investigación arqueológica", Anuario del Instituto de Estudios Zamoranos Florián de Ocampo, 23 (2006), págs. 51-76.

Pardo de Guevara Valdés, Eduardo, y García González-Ledo, Xosé Antón, Palos, fajas y jaqueles: la fusión de armerías en Galicia durante los siglos XIII al XVI, Lugo, Diputación Provincial, 1996.

Pardo de Guevara Valdés, Eduardo; Otero Piñeyro Maseda, Pablo Santiago, y García González-Ledo, Xosé Antón, "La huella de los primeros Ulloa en las torres y fortalezas de la terra de Ulloa", Castillos de España: publicación de la Asociación Española de Amigos de los Castillos [ejemplar monográfico de las fortificaciones galaicas], 164-166 (2012), págs. 59-67.

Pinilla González, Jaime, Castillos de Zamora y Salamanca, León, Lancia, 1995.

Quintanilla Raso, María Concepción, “Aportación al estudio de la Nobleza en la Edad Media: La Casa señorial de Benavides”, Historia. Instituciones. Documentos, 1 (1974), págs. 165-221.

Rius Serra, José, "Nuevos fueros de tierras de Zamora", Anuario de Historia del Derecho Español, 6 (1929), págs. 444-453.

Salgado Fuentes, Carlos Javier, La evolución de la identidad regional en los territorios del antiguo Reino de León (Salamanca, Zamora, León), Salamanca, Universidad de Salamanca, 2016. 
Sánchez González, Antonio, "La colección de Privilegios Rodados originales del Archivo Ducal de Medinaceli (1175-1458)", Lope de Barrientos. Seminario de Cultura, 2 (2009), págs. 217-279.

Sánchez González, Antonio, El Archivo de los Adelantados de Andalucía (Casa de Alcalá), Sevilla, Universidad de Sevilla, 2014.

Sánchez González, Antonio, El Archivo de los Caudillos del reino de Jaén (Casa de Santisteban del Puerto), Jaén, Diputación de Jaén, Instituto de Estudios Giennenses, 2015.

Sánchez González, Antonio, "Dos desconocidos reglamentos de archivos", Vegueta: Anuario de la Facultad de Geografía e Historia, 16 (2016), págs. 481-506.

Sánchez González, Antonio, "Papeles de ida y vuelta del virrey del Perú Diego de Benavides (1660-1666)", en Reyes Rojas (coord.), El Archivo General de Indias: El valor del documento y la escritura en el gobierno de América, Madrid, Ministerio de Cultura, 2016, págs. 239-250.

Sánchez González, Antonio (ed.), El arte de la representación del espacio: mapas y planos de la colección Medinaceli, Huelva, Universidad de Huelva, 2017 (Arias Montano, 125).

Sánchez González, Antonio, "El Hospital de San Juan Bautista en Toledo, una fundación familiar del Cardenal Tavera", Hispania Sacra (en prensa).

Sanz Fuentes, María Josefa, "Contribución a la sigilografía eclesiástica española: sellos de obispos zamoranos en la sección Villalonso del Archivo Ducal de Medinaceli”, Gades, 9 (1982), págs. 311-330.

Sanz Fuentes, María Josefa, "El señorío de Villalonso: aproximación diplomático-histórica", en El pasado histórico de Castilla y León: [Actas del I Congreso de Historia de Castilla y León celebrado en Valladolid, del 1 al 4 de diciembre de 1982]. Vol. 1: Edad Media, Burgos, Junta de Castilla y León, 1983, págs. 221-232.

Sanz Fuentes, María Josefa, "Villalonso, un castillo en las comunidades", Castillos de España: publicación de la Asociación Española de Amigos de los Castillos, 90 (1985), págs. 64-69.

Sanz Fuentes, María Josefa, "Un noble zamorano ante la muerte: testamento, codicilo e inventario post mortem de Diego Ulloa, Señor de Villalonso", en Primer congreso de historia de Zamora. T. I: Fuentes documentales, Zamora, Instituto de Estudios Zamoranos Florián de Ocampo, 1989, págs. 369-388.

Suárez Fernández, Luis, Los Reyes Católicos: la conquista del trono, Madrid, Rialp, 1989. 


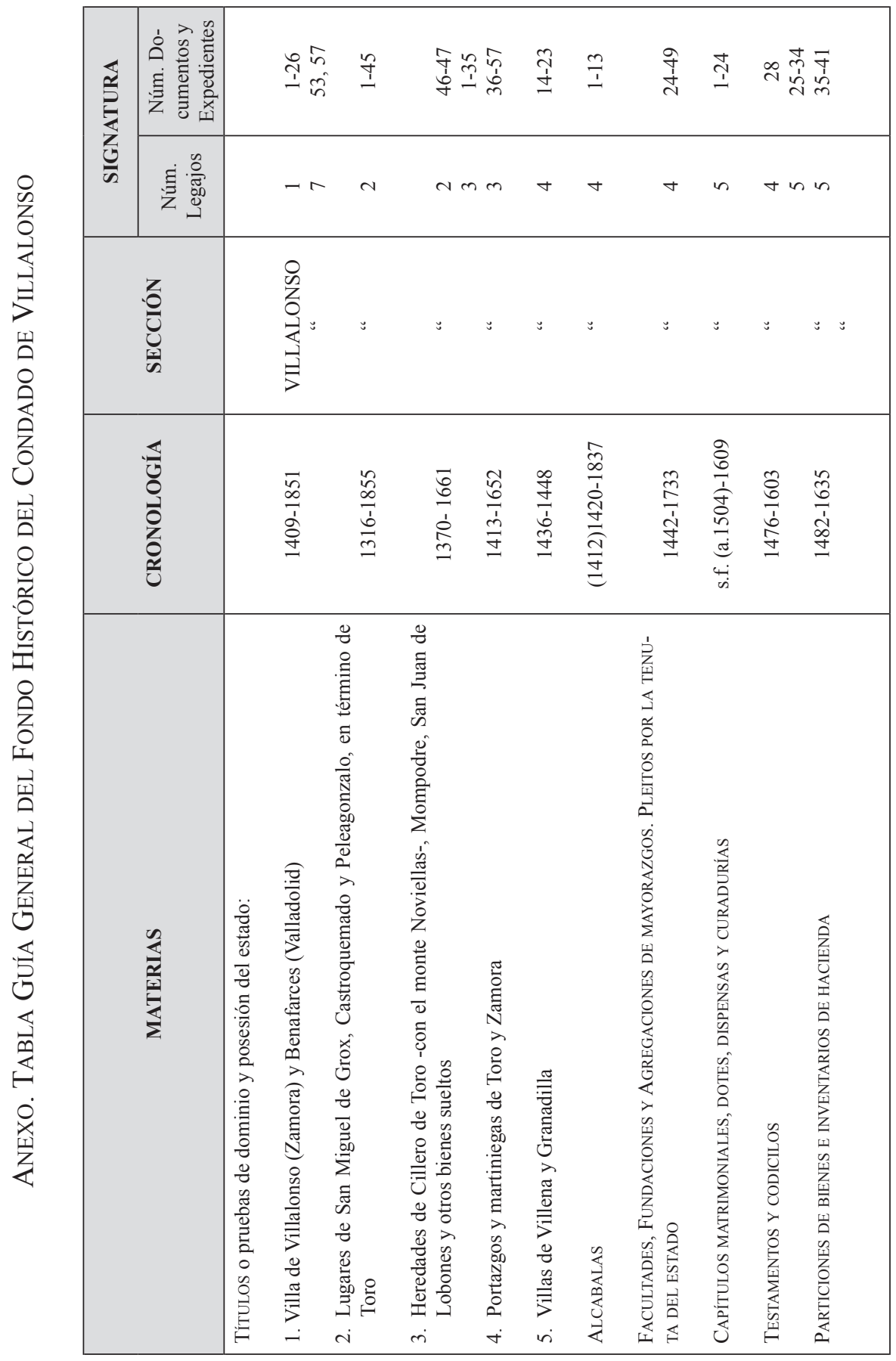


DOCUMENTOS DE LOS ULLOA:

\begin{tabular}{|c|c|c|c|c|c|c|c|c|c|c|c|c|}
\hline \multirow{2}{*}{$\frac{\mathbb{s}}{\sum_{0}^{2}}$} & 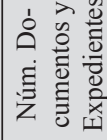 & \multicolumn{5}{|c|}{ 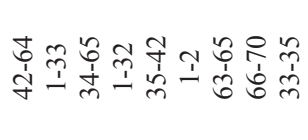 } & \multicolumn{3}{|c|}{ 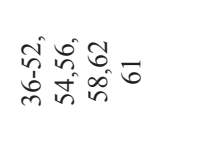 } & \multicolumn{2}{|c|}{ in in } & \multirow[t]{2}{*}{ i } \\
\hline & 实 造 & & 0 & $\simeq \exists$ & 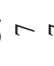 & & & $r$ & & $+r$ & $r$ & \\
\hline & 믈 & 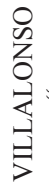 & s & 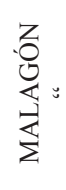 & 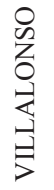 & : & : & : & & $\because=$ & $\because:$ & s \\
\hline & 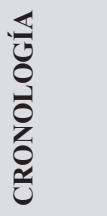 & 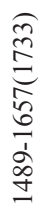 & & \begin{tabular}{l}
$\infty$ \\
$\infty$ \\
$\infty$ \\
\multirow{1}{1}{} \\
\multirow{0}{0}{}
\end{tabular} & $\begin{array}{l}\vec{\Xi} \\
\stackrel{+}{\dot{+}} \\
\stackrel{\infty}{-1}\end{array}$ & $\begin{array}{l}2 \\
\stackrel{0}{1} \\
\infty \\
\infty \\
\text { d }\end{array}$ & $\begin{array}{l}0 \\
n \\
\infty \\
\infty \\
\infty \\
\infty \\
1\end{array}$ & $\stackrel{\infty}{+\infty}$ & & 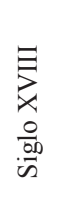 & $\begin{array}{l}\frac{n}{\infty} \\
\frac{\infty}{1} \\
\infty \\
\infty\end{array}$ & $\begin{array}{l}x \\
x \\
0 \\
.00 \\
0\end{array}$ \\
\hline & $\begin{array}{l}\frac{n}{3} \\
\frac{2}{x=1} \\
\sum\end{array}$ & $\begin{array}{l}n \\
0 \\
0 \\
\sum_{1}^{n} \\
\text { U }\end{array}$ & 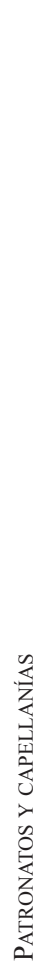 & 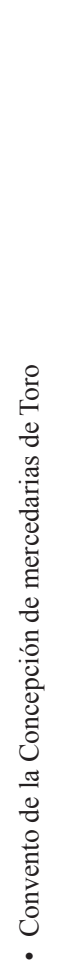 & 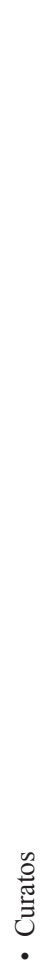 & 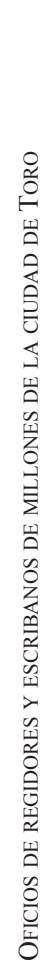 & 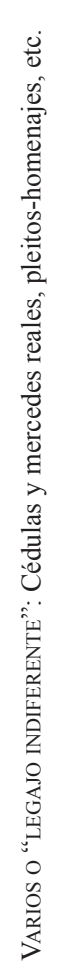 & 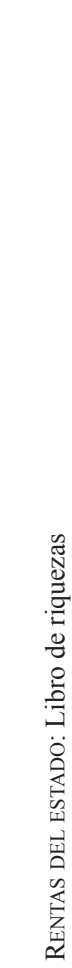 & 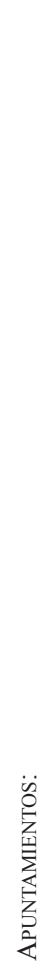 & 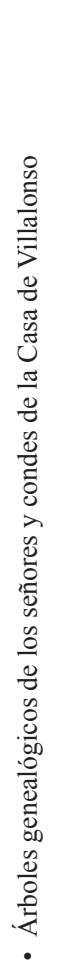 & 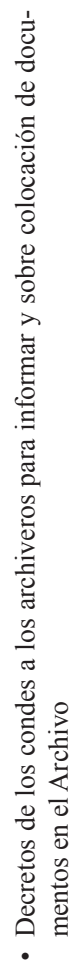 & 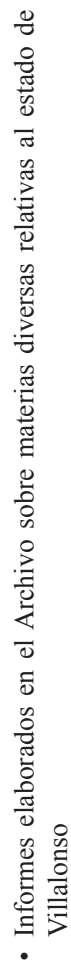 \\
\hline
\end{tabular}


